\title{
A COMPARATIVE DIACHRONICALANALYSIS OF THE CONCEPT TOLERANCE IN THE ENGLISH LANGUAGE SPEAKERS CONSCIOUSNESS
}

\author{
Nadezhda A. Nerovnaya \\ Military Educational and Scientific Center of the Air Force N.E. Zhukovsky and Yu.A. Gagarin Air Force Academy, \\ Voronezh, Russia
}

\begin{abstract}
The article is devoted to semantic and cognitive analysis of the tolerance concept in the English language native speakers' consciousness. A comparison of the data on tolerance obtained in publicist texts in 20072009 and in 2014-2016 revealed stable cognitive signs which proves the supposition that the concept under study is deeply rooted in the consciousness of native speakers of the English language. However, new cognitive signs and the signs which were not detected in 2007-2009, were noticed, thus pointing to reinterpretation of the tolerance concept. The field stratification of the concept was based on a traditional model with a nuclear and close, far, extreme periphery zones, into which the means that denote tolerance were included, whereas they are thought being different by the cognitive index of brightness. The studies highlighted one important trend - the increase index of negative appraisement which is the testimony to the fact that the attitude of the English language native speakers to the concept under investigation has negatively changed. The author comes to the conclusion that the concept is communicatively relevant and dynamic. The positive appraisement in the concept 'tolerance' structure prevails.

Key words: concept, semantics, language consciousness, cognitive sign, objectivation, field stratification, index of brightness, tolerance.

Citation. Nerovnaya N.A. A Comparative Diachronical Analysis of the Concept Tolerance in the English Language Speakers Consciousness. Vestnik Volgogradskogo gosudarstvennogo universiteta. Seriya 2, Yazykoznanie [Science Journal of Volgograd State University. Linguistics], 2018, vol. 17, no. 2, pp. 126-133. (in Russian). DOI: https://doi.org/10.15688/jvolsu2.2018.2.14
\end{abstract}

\section{СОДЕРЖАНИЕ КОНЦЕПТА «ТОЛЕРАНТНОСТЬ» В АНГЛИЙСКОМ ЯЗЫКОВОМ СОЗНАНИИ: ДИНАМИЧЕСКИЙ АСПЕКТ}

\section{Надежда Александровна Неровная}

Военный учебно-научный центр Военно-воздушных сил «Военно-воздушная академия им. профессора Н.Е. Жуковского и Ю.А. Гагарина», г. Воронеж, Россия

\footnotetext{
Аннотация. Статья посвящена семантико-когнитивному изучению концепта «толерантность» в английском языковом сознании на материале публицистических текстов, посвященных проблеме толерантности, которые были размещены на сайтах англоязычных СМИ в 2014-2016 годах. Эти результаты сопоставлены с результатами исследования автора, проведенного на материале публикаций 2007-2009 годов. В ходе анализа выявлены стабильные когнитивные признаки, представленные в публикациях обоих временных срезов и свидетельствующие об укоренении данного концепта в сознании носителей языка, а также новые когнитивные признаки и признаки, не получившие отражения в публицистических текстах 2014-2016 гг, их наличие является доказательством переосмысления концепта. С учетом полученных новых данных и в зависимости от индекса яркости когнитивных признаков осуществлена полевая стратификация концепта «толерантность» -
} 
выделено ядро, ближняя, дальняя и крайняя периферии. Показано возрастание негативной оценочности когнитивных признаков концепта, свидетельствующее о смещении отношения к толерантности в отрицательную сторону. Сделан вывод о коммуникативной релевантности, динамичности концепта «толерантность» и о преобладании в его структуре признаков, отражающих его позитивную оценку в английском языковом сознании.

Ключевые слова: концепт, семантика, языковое сознание, когнитивный признак, объективация, полевая стратификация, индекс яркости, толерантность.

Цитирование. Неровная Н. А. Содержание концепта «толерантность» в английском языковом сознании: динамический аспект // Вестник Волгоградского государственного университета. Серия 2, Языкознание. -2018. - Т. 17, № 2. - С. 126-133. - DOI: https://doi.org/10.15688/jvolsu2.2018.2.14

\section{Введение}

Изучение концепта «толерантность»в отечественной лингвистике имеет определенные достижения: описана его структура [Ли Же, 2009], он охарактеризован в лингвокультурном [Сумина, 2007] и когнитивно-дискурсивном [Аболин, 2006] аспектах. Цель нашей работы - выявить изменения содержания концепта «толерантность» в английском языковом сознании. В 2007-2009 гг. нами было проведено обширное исследование данного концепта; результаты нашли отражение в публикациях (см., например: [Неровная, 2008]) и обобщены в кандидатской диссертации «Национальная специфика лексико-фразеологической объективации близких по содержанию концептов (на материале концептов “толерантность”, “терпимость” в русском и английском языковом сознании)» [Неровная, 2009]. Кроме того, в 2016 г. нами был проведен сравнительный анализ содержания концепта «толерантность» в русском языковом сознании в динамическом аспекте, что позволило выявить ряд его существенных изменений и закономерностей развития [Неровная, 2017].

В 2007-2016 гг. значительные перемены затронули практически все сферы жизни населения европейских стран. Страх перед терроризмом, отсутствие единства в обществе и социальные беспорядки привели к тому, что все чаще высказывается мнение о проявлении излишней толерантности по отношению к меньшинствам в ущерб правам большинства. Толерантность стала рассматриваться как причина социальных проблем, признак слабости и социальных беспорядков [Dobbernack, Modood, 2012, p. 8].

Мы предположили, что эти явления оказали влияние на содержание данного концеп- та в английском языковом сознании и его номинативное поле может содержать объективации, не зафиксированные в ходе исследования, проведенного нами в 2007-2009 гг., и что они могут изменить структуру концепта и его оценочную характеристику.

\section{Методика исследования}

Исследование выполнено в русле семантико-когнитивного направления лингвистики, которое, согласно З.Д. Поповой и И.А. Стернину, рассматривает лексическую и грамматическую семантику языка как средство доступа к содержанию концептов, соотношение семантических процессов с когнитивными [Попова, Стернин, 2007a, с. 12-13].

Для подтверждения гипотезы мы проанализировали публицистические тематические тексты, посвященные проблеме толерантности, которые размещены на сайтах новостного портала BBC, газет «The Daily Mail», «The Independent», «The Telegraph» в 2014-2016 годах. Всего было обнаружено 582 документа и 610 контекстов употребления лексемы tolerance. В связи с тем что некоторые примеры содержали больше чем одну объективацию изучаемого концепта, было выделено 636 объективаций концепта «толерантность». Полученные объективации были подвергнуты когнитивной интерпретации, в результате которой выделено 53 когнитивных признака, а также вычислен их индекс яркости. Под когнитивным признаком, согласно 3.Д. Поповой и И.А. Стернину, понимается «отдельный признак объекта, осознанный человеком и отображенный в структуре соответствующего концепта как отдельный элемент его содержания» [Попова, Стернин, 2007б, с. 90]. Объективации - это «любые номинации ис- 


\section{МАТЕРИАЛЫ И СООБЩЕНИЯ}

следуемого концепта, включая окказиональные, индивидуально-авторские, описательные» [Попова, Стернин, 2007б, с. 126]. Индекс яркости вычислялся как отношение количества объективаций, входящих в данный когнитивный признак, к общему количеству объективаций в текстах [Попова, Стернин, 2007б, с. 121].

Например, когнитивный признак 'выражается по отношению к негативным явлениям' представлен 52 объективациями, которые составляют примерно $8 \%$ от общего количества объективаций (636), установленных в ходе настоящего исследования: tolerance for human death - 3; for ambiguity, of alcoholfuelled behavior, for feelings of uncertainty, of anti-social behavior, for abuse - 2; to conflict, for non-stop music, for critics, for the arrival of thousands of Kurds, for regressive practices in other cultures, for repugnant practices in other cultures, for hypocrisy, for boredom, for the consequences of war, of failure, to stalkerish behavior, of predatory attitudes towards women, for marriage of convenience, for internecine nastiness, of displays of scantily dressed women, to loose arrangements, of totalitarian behavior, to disparaging remarks, of bigotry, for hateful public display, for our degree of economic inequality, to oligarchy, for a racist message, for laziness, for vulnerable individuals, for violence, for domestic political dissent, of Russia's aggression, for mob violence, for unequal access to the resources, for controversy, of the sensations of anxiety, for blood, for guts, for dead giants, for hallmarks of grim medieval battle, for misbehavior, for failure, for controversy - 1 .

Далее было осуществлено сравнение полученных результатов с данными анализа англоязычных публицистических тематических текстов, размещенных на указанных сайтах в 2007-2009 годах.

\section{Результаты и обсуждение}

Проведенное сравнение позволило сделать ряд выводов.

1. Общее количество объективаций увеличилось (636 против 478), а количество когнитивных признаков, наоборот, уменьшилось
(52 против 67). Это свидетельствует о расширении содержания концепта, его большей структуризации: упорядочивании групп вербальных единиц, выражающих тот или иной когнитивный признак, а следовательно, о конкретизации смысла концепта в сознании носителей английского языка.

2. Совпадают следующие 10 когнитивных признаков: 'обязанность человека', 'воспитывается с помощью разных педагогических приемов', 'признание права на свободное вероисповедание', 'принятие многообразия форм самовыражения', 'проявление культуры', 'проявляется в сфере политики', 'проявляется по отношению к другому', 'является необходимой людям', 'социально-политическое требование', 'проявляется во взаимности'. Такие сохраняющиеся признаки, отражающие укоренение данного концепта в сознании носителей языка, мы предложили называть стабильными [Неровная, 2017, c. 40].

3. Среди перечисленных стабильных когнитивных признаков повысили яркость такие признаки, как 'признание права на свободное вероисповедание' (индекс яркости (далее ИЯ) изменился с 0,01 на 0,03), 'воспитывается с помощью разных педагогических приемов' (ИЯ изменился с 0,01 на 0,02), 'проявляется по отношению к другому' (ИЯ изменился с 0,03, на 0,10). Данный факт свидетельствует в пользу повышения структурной значимости этих когнитивных признаков концепта в сознании носителей языка. Остальные стабильные признаки не изменили свой ИЯ: он остался на уровне 0,01 .

4. Новыми когнитивными признаками, выявленными в ходе исследования, стали следующие 45 признаков (в скобках указан ИЯ): 'может отсутствовать по отношению к нарушению закона' $(0,16)$, 'может проявляться в разной степени' $(0,10)$, 'выражается по отношению к негативным явлениям' $(0,09)$, 'ее распространяют разными способами' $(0,08)$, 'проявляется в сфере религии' $(0,05)$, 'является добродетелью’ $(0,04)$, 'выражается по отношению к нарушениям закона' $(0,03)$, 'нуждается в защите' $(0,03)$, 'демонстрируется' $(0,03)$, 'есть в Великобритании' $(0,03)$, 'является предметом гордости' $(0,02)$, 'проявляется во взаимности' $(0,01)$, 'от нее отказывают- 
ся' $(0,01)$, 'находится под угрозой' $(0,01)$, 'ее недостаточно' $(0,01)$, 'является посланием' $(0,01)$, 'является негативным качеством' $(0,01)$, 'обсуждается' $(0,01)$, 'является предметом веры' $(0,01)$, 'имеет пассивное проявление' $(0,01)$, 'доставляет удовольствие' $(0,01)$, 'проявляется в сфере образования' $(0,01)$, 'обладает историей' $(0,01)$, 'есть в Канаде' $(0,01)$, 'есть на Западе' $(0,01)$, 'проявление культуры' $(0,01)$, 'проявляется по отношению к другой культуре' $(0,01)$, 'проявляется по отношению к риску' $(0,01)$, 'обладает стандартом' $(0,01)$, ‘проявляется в отношениях' $(0,01)$, 'обладает символами' $(0,01)$, ‘не допускается по отношению к другому мнению' $(0,01)$, 'есть в США' $(0,01)$, 'создает репутацию' $(0,01)$, ‘проявляется по отношению к работе' $(0,01)$, 'пользуется любовью' $(0,01)$, 'подвергается разрушению' $(0,01)$, 'приводит к положительному результату' $(0,01)$, 'проявляется властями' $(0,01)$, 'вызывает уважение' $(0,01)$, 'проявление человечности' $(0,01)$, 'обладает преимуществами' $(0,01)$, 'является основой будущего' $(0,01)$.

5. В текстах 2014-2016 гг. не были зафиксированы признаки, выявленные в ходе анализа текстов, опубликованных в 20072009 гг.: 'уважительное отношение к многообразию' $(0,12)$, ‘проявление доброты' $(0,06)$, 'отсутствие предвзятости' $(0,06)$, 'положительное отношение к многообразию’ $(0,04)$, 'признание равенства' $(0,04)$, 'снисходительность, мягкость по отношению к другому' $(0,03)$, 'проявление нравственности' $(0,03)$, 'понимание многообразия форм самовыражения' $(0,03)$, 'готовность мирно сосуществовать с другим' $(0,02)$, 'допущение многообразия форм самовыражения’ $(0,02)$, 'признание многообразия форм самовыражения' $(0,02)$, 'смирение с чем-л. неприятным' $(0,02)$, 'обусловлена уважением прав человека' $(0,02)$, 'проявляется в свободе' $(0,02)$, 'умение ценить многообразие' $(0,02)$, 'осознание многообразия' $(0,01)$, 'отказ от вмешательства в личную жизнь' $(0,01)$, 'отказ от осуждения действий кого-л.' $(0,01)$, 'отрицание абсолютизма' $(0,01)$, 'отсутствие дискриминации' $(0,01)$, 'отсутствие догматичности' $(0,01)$, 'отсутствие надоедливости' $(0,01)$, 'отсутствие оппозиции многообразию’ $(0,01)$, 'отсутствие принуждения' $(0,01)$, 'предостав- ление шанса' $(0,01)$, 'приводит к единению' $(0,01)$, 'приобретенное качество' $(0,01)$, 'проявление вежливости' $(0,01)$, 'проявление любви' $(0,01)$, 'проявление открытости' $(0,01)$, 'проявляется в действии' $(0,01)$, 'проявляется в способности прощать' $(0,01)$, 'проявляется как гармония в различии' $(0,01)$, 'проявляется как ментальное состояние' $(0,01)$, 'проявляется по отношению к личности' $(0,01)$, 'проявляется по отношению к мысли, замыслу' $(0,01)$, 'свобода от фанатизма' $(0,01)$, 'ассоциируется с сердцем' $(0,01)$, 'вера в хорошее' $(0,01)$, 'выражается в плюрализме' $(0,01)$, 'выражается в поддержке многообразия' $(0,01)$, 'выражается в цивилизованности' $(0,01)$, 'способ эффективной борьбы с расизмом' $(0,01)$, 'способность выживать' $(0,01)$, 'способность делиться с другими' $(0,01)$, 'является единственным абсолютом общества' $(0,01)$, 'желание учиться у других' $(0,01)$, 'имеет невысокую цену' $(0,01)$, 'интерес к многообразию' $(0,01)$, 'либеральное отношение к многообразию' $(0,01)$, 'обусловлена наличием демократии' $(0,01)$, 'обусловлена наличием независимости' $(0,01)$. Такой результат свидетельствует о значительном снижении или утрате перечисленными когнитивными признаками их актуальности для носителей английского языка.

6. С учетом полученных данных концепт «толерантность» может быть структурирован как поле (см. таблицу). Критерием разграничения ядра и периферии является индекс яркости признака (совокупный индекс яркости когнитивных признаков концепта, образующих ядро или периферию, указан в скобках, процентное выражение количества когнитивных признаков определяется относительно общего количества когнитивных признаков концепта).

7. Исследование показывает изменение ядра концепта «толерантность»: если прежде его образовывал такой признак, как 'уважительное отношение к многообразию’ $(0,12)$ [Неровная, 2008, с. 85], то теперь ядро образуют когнитивные признаки 'может отсутствовать по отношению к нарушению закона' $(0,16)$ и 'может проявляться в разной степени' $(0,10)$. Данный факт свидетельствует об изменениях в осмыслении толерантности носителями английского языка. 
Полевая структура концепта «толерантность»

\begin{tabular}{|c|c|c|}
\hline $\begin{array}{c}\text { № } \\
\Pi / \Pi\end{array}$ & Когнитивный признак & $\begin{array}{l}\text { Индекс } \\
\text { яркости }\end{array}$ \\
\hline & \multicolumn{2}{|l|}{ Ядро (0,26) 3,8 \% } \\
\hline 1 & Может отсутствовать по отношению к нарушению закона & 0,16 \\
\hline 2 & Может проявляться в разной степени & 0,10 \\
\hline \multicolumn{3}{|c|}{ Ближняя периферия $(0,51) 21,2$ \% } \\
\hline 3 & Выражается по отношению к негативным явлениям & 0,08 \\
\hline 4 & Проявляется по отношению к другому & 0,08 \\
\hline 5 & Ее распространяют разными способами & 0,08 \\
\hline 6 & Проявляется в сфере религии & 0,05 \\
\hline 7 & Является ценностью & 0,04 \\
\hline 8 & Признание права на свободное вероисповедание & 0,03 \\
\hline 9 & Является частью общества & 0,03 \\
\hline 10 & Нуждается в защите & 0,03 \\
\hline 11 & Демонстрируется & 0,03 \\
\hline 12 & Есть в Великобритании & 0,03 \\
\hline 13 & Выражается по отношению к нарушениям закона & 0,03 \\
\hline \multicolumn{3}{|c|}{ Дальняя периферия (0,04) 3,8 \% } \\
\hline 14 & Является предметом гордости & 0,02 \\
\hline 15 & Воспитывается с помощью разных педагогических приемов & 0,02 \\
\hline \multicolumn{3}{|c|}{ Крайняя периферия $(0,37) 71,2 \%$} \\
\hline 16 & Проявляется во взаимности & 0,01 \\
\hline 17 & От нее отказываются & 0,01 \\
\hline 18 & Находится под угрозой & 0,01 \\
\hline 19 & Ее недостаточно & 0,01 \\
\hline 20 & Является посланием & 0,01 \\
\hline 21 & Обсуждается & 0,01 \\
\hline 22 & Является предметом веры & 0,01 \\
\hline 23 & Является негативным качеством & 0,01 \\
\hline 24 & Проявляется по отношению к риску & 0,01 \\
\hline 25 & Доставляет удовольствие & 0,01 \\
\hline 26 & Проявляется в сфере образования & 0,01 \\
\hline 27 & Обладает историей & 0,01 \\
\hline 28 & Есть в Канаде & 0,01 \\
\hline 29 & Имеет пассивное проявление & 0,01 \\
\hline 30 & Есть на Западе & 0,01 \\
\hline 31 & Проявление культуры & 0,01 \\
\hline 32 & Проявляется по отношению к другой культуре & 0,01 \\
\hline 33 & Является необходимой людям & 0,01 \\
\hline 34 & Принятие многообразия форм самовыражения & 0,01 \\
\hline 35 & Обладает стандартом & 0,01 \\
\hline 36 & Проявляется в отношениях & 0,01 \\
\hline 37 & Социально-политическое требование & 0,01 \\
\hline 38 & Обладает символами & 0,01 \\
\hline 39 & Не допускается по отношению к другому мнению & 0,01 \\
\hline 40 & Есть в США & 0,01 \\
\hline 41 & Создает репутацию & 0,01 \\
\hline 42 & Проявляется в сфере политики & 0,01 \\
\hline 43 & Проявляется по отношению к работе & 0,01 \\
\hline 44 & Пользуется любовью & 0,01 \\
\hline 45 & Подвергается разрушению & 0,01 \\
\hline 46 & Приводит к положительному результату & 0,01 \\
\hline 47 & Средство борьбы с терроризмом & 0,01 \\
\hline 48 & Обладает преимуществами & 0,01 \\
\hline 49 & Вызывает уважение & 0,01 \\
\hline 50 & Проявляется властями & 0,01 \\
\hline 51 & Проявление человечности & 0,01 \\
\hline 52 & Является основой будущего & 0,01 \\
\hline
\end{tabular}


8. В результате исследования установлено резкое возрастание негативно-оценочных признаков. Если в текстовом материале 20072009 гг. был зафиксирован только 1 негативнооценочный признак в восприятии толерантности - 'имеет невысокую цену' $(0,01)$, то в текстах 2014-2017 гг. их выявлено 11 (21,0\% от общего количества (52) признаков, зафиксированных в 2014-2016 гг.). Это такие признаки, как 'может отсутствовать по отношению к нарушению закона' $(0,16)$, 'выражается по отношению к негативным явлениям' $(0,08)$, 'выражается по отношению к нарушениям закона' $(0,03)$, 'нуждается в защите' $(0,03)$, 'от нее отказываются' $(0,01)$, 'находится под угрозой' $(0,01)$, ‘ее недостаточно’ $(0,01)$, ‘является негативным качеством' $(0,01)$, 'не допускается по отношению к другому мнению’ $(0,01)$, ‘имеет пассивное проявление' $(0,01)$, 'подвергается разрушению’ $(0,01)$. Особенно важным является тот факт, что негативную оценочность имеет признак 'может отсутствовать по отношению к нарушению закона’ $(0,16)$, характеризующийся наибольшим индексом яркости и образующий ядро исследуемого концепта. Сам факт того, что толерантность может отсутствовать, несет негативную коннотацию в западной культуре. Если раньше такие словосочетания, как zero tolerance, no tolerance, встречались довольно редко, то в последнее время частотность их употребления возросла. Это свидетельствует о более критичном отношении носителей языка к такому явлению, как толерантность, и смещении отношения к нему в сторону негативной оценки.

9. Когнитивных признаков, имеющих позитивную оценку, выявлено 23 (35 \% от общего количества (66) признаков, зафиксированных в 2014-2016 гг.): 'проявляется по отношению к другому' $(0,08)$, 'ее распространяют разными способами' $(0,08)$, 'проявляется в сфере религии' $(0,05)$, 'является ценностью' $(0,04)$, 'признание права на свободное вероисповедание' $(0,03)$, 'является предметом гордости' $(0,02)$, 'воспитывается с помощью разных педагогических приемов' $(0,02)$, 'проявляется во взаимности' $(0,01)$, 'является предметом веры' $(0,01)$, 'доставляет удовольствие' $(0,01)$, 'проявление культуры' $(0,01)$, 'проявляется по отношению к другой культуре’ $(0,01)$, 'является необходимой людям' $(0,01)$, 'приня- тие многообразия форм самовыражения' $(0,01)$, 'обладает стандартом' $(0,01)$, 'социально-политическое требование' $(0,01)$, 'пользуется любовью’ $(0,01)$, ‘приводит к положительному результату' (0,01), 'средство борьбы с терроризмом' $(0,01)$, 'обладает преимуществами' (0,01), 'вызывает уважение' $(0,01)$, 'проявление человечности' $(0,01)$, 'является основой будущего' $(0,01)$.

10. Неоценочный слой составляют 18 (27 \% от общего количества) когнитивных признаков, таких как 'может проявляться в разной степени' $(0,10)$, 'является частью общества' $(0,03)$, ‘демонстрируется’ $(0,03)$, 'есть в Великобритании’ $(0,03)$, 'является посланием’ $(0,01)$, 'обсуждается' $(0,01)$, ‘проявляется по отношению к риску' $(0,01)$, 'проявляется в сфере образования’ $(0,01)$, 'обладает историей’ $(0,01)$, 'есть в Канаде' $(0,01)$, 'есть на Западе' $(0,01)$, 'проявляется в отношениях' $(0,01)$, 'обладает символами' $(0,01)$, 'есть в США' $(0,01)$, 'создает репутацию’ $(0,01)$, ‘проявляется в сфере политики' $(0,01)$, 'проявляется по отношению к работе’ $(0,01)$, ‘проявляется властями’ $(0,01)$.

\section{Выводы}

Высокая текстовая рекуррентность, обширное номинативное поле, а также объемное и разнообразное когнитивное содержание, позволяющее выделить ядро, ближнюю, дальнюю и крайнюю периферии, свидетельствуют о том, что исследуемый концепт имеет выраженную коммуникативную значимость и актуален для английского языкового сознания. Результаты проведенного сравнения, позволившего нам обнаружить стабильные когнитивные признаки, свидетельствуют об укоренении концепта в сознании носителей английского языка. Тем не менее тот факт, что в ходе исследования было выявлено большое количество новых когнитивных признаков и не зафиксированы ранее установленные признаки, указывает на динамичность концепта, который подвергается переосмыслению. Глубокие социально-экономические и политические изменения в жизни Европы, по-видимому, обусловили изменение отношения носителей английского языка к толерантности в отрицательную сторону. Однако в целом позитивная оценка преобладает, следовательно, концепт «толеран- 
тность» в сознании носителей английского языка является позитивно-оценочным.

\section{СПИСОК ЛИТЕРАТУРЫ}

Аболин Б. И., 2006. Компоненты языковой модели толерантного отношения (на материале ядерных репрезентантов концепта «толерантность» в русском языке) // Проблемы языковой концептуализации и категоризации действительности : материалы Всерос. науч. конф. «Язык. Система. Личность». Екатеринбург : Изд-во Урал. пед. ун-та. С. 6-10.

Ли Же, 2009. Толерантность // Антология концептов : сб. науч. работ. Волгоград : Парадигма. Т. 7. С. 70-79.

Неровная Н. А., 2008. Концепт «толерантность» в публицистических источниках на русском и английском языках // Вестник Воронежского университета. Серия: Филология и журналистика. № 2. С. 84-87.

Неровная Н. А., 2009. Национальная специфика лексико-фразеологической объективации близких по содержанию концептов (на материале концептов толерантность, терпимость в русском и английском языковом сознании) : дис. ... канд. филол. наук. Воронеж. 252 с.

Неровная Н. А., 2017. Диахроническое сравнение содержания концепта «толерантность» в русском языковом сознании // Вестник Пермского университета. Серия: Российская и зарубежная филология. Т. 9, вып. 2. С. 39-46.

Попова З. Д., Стернин И. А., 2007а. Семантико-когнитивный анализ языка. Воронеж : Истоки. $252 \mathrm{c}$.

Попова З. Д., Стернин И. А., 2007б. Когнитивная лингвистика. М. : АСТ : Восток-Запад. 226 с.

Сумина Е. С., 2007. Толерантность: от феномена к лингвокультурному концепту : автореф. дис. ... канд. филол. наук. Екатеринбург. $21 \mathrm{c.}$

Dobbernack J., Modood T., 2012. Tolerance and cultural diversity in Europe: Theoretical perspectives and contemporary developments. Florence : European University Institute. 35 p.

\section{ИСТОЧНИКИ}

BBC. URL: http://www.bbc.com (date of access: 20.08.2016).

The Daily Mail Online. URL: http:/www.dailymail. co.uk/home/index.html (date of access: 18.09.2016).

The Independent. URL: http://www.independent.co.uk (date of access: 26.10.2016).

The Telegraph. URL: http://www.telegraph.co.uk (date of access: 15.11.2016).

\section{REFERENCES}

Abolin B.I., 2006. Components of the language model of tolerant attitude (on the material of nuclear representatives of the concept 'tolerance' in the Russian language). Problemy yazykovoy kontseptualizatsii i kategorizatsii deystvitelnosti: materialy Vseros. nauch. konf. «Yazyk. Sistema. Lichnost». Ekaterinburg, Izd-vo Ural. Ped. Un-ta, pp. 6-10.

Li Zhe, 2009. Tolerance. Antologiya kontseptov: $s$. nauch. rabot. Volgograd, Paradigma Publ., vol. 7, pp. 70-79.

Nerovnaya N.A., 2008. The concept 'tolerance' in the Russian and English language journalistic sources. Vestnik Voronezhskogo universiteta. Seriya: Filologiya i zhurnalistika [Proceedings of Voronezh State University. Series, Philology. Journalism], no. 2, pp. 84-87.

Nerovnaya N.A., 2009. The national specificity of lexical and phraseological objectivation of concepts close in content (on the material of the concepts 'tolerance', 'indulgence' in the Russian and English language consciousness). PhD Thesis. Voronezh. 252 p.

Nerovnaya N.A., 2017. Diachronic comparison of the concept 'tolerance' in the Russian consciousness. Vestnik Permskogo universiteta. Seriya: Rossiyskaya $i$ zarubezhnaya filologiya [Perm University Herald. Russian and Foreign Philology], vol. 9, iss. 2, pp. 39-46.

Popova Z.D., Sternin I.A., 2007a. Semantic and cognitive analysis of language. Voronezh, Istoki Publ. 252 p.

Popova Z.D., Sternin I.A., 2007b. Cognitive linguistics. Moscow, AST; Vostok-Zapad Publ. 226 p.

Sumina E.S., 2007. Tolerance: from phenomenon to linguocultural concept. Abstract of PhD Thesis. Ekaterinburg. 21 p.

Dobbernack J., Modood T., 2012. Tolerance and cultural diversity in Europe: Theoretical perspectives and contemporary developments. Florence, European University Institute. 35 p.

\section{SOURCES}

$B B C$. URL: http://www.bbc.com (accessed 20 August 2016).

The Daily Mail Online. URL:http://www.dailymail. co.uk/home/index.html (accessed 18 September 2016).

The Independent. URL: http://www.independent.co.uk (accessed 26 October 2016).

The Telegraph. URL: http://www.telegraph.co.uk (accessed 15 November 2016). 
Н.А. Неровная. Содержание концепта «толерантность» в английском языковом сознании

\section{Information about the Author}

Nadezhda A. Nerovnaya, Candidate of Sciences (Philology), Associate Professor, Department of Foreign Languages, Military Educational and Scientific Center of the Air Force N.E. Zhukovsky and Yu.A. Gagarin Air Force Academy, Starykh Bolshevikov St., 54a, 394064 Voronezh, Russia, nnerovnaya@yandex.ru,https://orcid.org/0000-0002-8782-0903

\section{Информация об авторе}

Надежда Александровна Неровная, кандидат филологических наук, доцент кафедры иностранных языков, Военный учебно-научный центр Военно-воздушных сил «Военно-воздушная академия им. профессора Н.Е. Жуковского и Ю.А. Гагарина», ул. Старых Большевиков, 54а, 394064 г. Воронеж, Россия, nnerovnaya@yandex.ru, https://orcid.org/0000-0002-8782-0903 